\title{
Evaluation on the Potential Use of Shotcrete Lined High Pressure Tunnel at Upper Tamakoshi Hydroelectric Project
}

Abstract: Optimization of rock support is a key factor for successful use of underground space for hydropower development in the Himalaya. Therefore, finding innovative, optimum and economic solution will be the only way to guarantee such optimization. A main issue is to determine the extent of hydraulic fracturing and assess the water leakage possibility during the operation of such tunnels. The leaked water not only causes economic loss but also may severely affect the stability of tunnel, valley side slopes and the environment.

The use of fully concrete/steel lined pressure tunnels against hydraulic fracturing in the rock mass is a costly alternative. Hence, it is advantageous to explore possibilities of minimizing the length of the concrete or steel lining in high pressure tunnels and shafts. A proper assessment of hydraulic fracturing of the rock mass plays an important role in this endeavor.

This paper evaluates whether or not hydraulic fracturing (splitting) will occur at the 4,746m long shotcrete-lined high pressure headrace tunnel of 456 MW Upper Tamakoshi Hydroelectric Project (UTKHEP). The Upper Tamakoshi HEP is a high head project (gross head $822 \mathrm{~m}$ ) and the proposed shotcrete lined high pressure headrace tunnel will experience maximum hydrostatic pressure head of 40 bar ( $400 \mathrm{~m}$ water column) at normal plant operation. To check the possibility of hydraulic fracturing, both deterministic and two dimensional numerical modeling techniques have been used. In addition, the paper also highlights the importance and challenges to be faced while estimating representative input variables needed for both deterministic and numerical modeling.

Key words: Hydraulic fracturing, high pressure tunnel, shotcrete lining, Upper Tamakoshi Hydropower Project, Nepal

\section{Introduction}

$\mathbf{H}$ ydraulic fracturing in pressure tunnels occurs when the internal water pressure imposed to the rock mass exceeds the minor principal stress. When water pressure more than the in-situ stress is acting on the rock mass, the existing joints on areas where the pressure is acting are opened and the movement of rock mass around the tunnel periphery occurs depending on the deformability characteristics of the rock mass. This results in the excessive leakage as well as instability in the tunnel.

The conventional design approach for high pressure tunnels in the early era of hydropower development was to carry out full concrete or steel lining, which in many occasions is still prevailing. However, this approach is an expensive and time consuming solution. After the First World War, the price of steel in Europe was very high, which led to difficulties in developing hydropower projects in Norway; a country in desperate need for energy for its industrialization. As an attempt to come out of this difficulty, some high pressure shafts of the hydropower plants were put directly into operation (without any steel lining) during the years 1919-21. The water heads in these projects varied from 72 to $152 \mathrm{~m}$. Since then, various advances have been made in this field and most of the pressure tunnels and shaft built in Norway are left unlined (Edvardsson and Broch 2002).

Numerous existing hydroelectric plants have heads beyond $1000 \mathrm{~m}$, and projects are now heading more than $1500 \mathrm{~m}$. Modern practice for such projects is to provide shorter steel liners, subjecting long unlined portions of tunnels to high hydrostatic pressures (Benson, 1989). This implies that there will be significant reduction in the project cost and construction time which improves the projects' financial situation.

On the other hand, pressure tunnels should also be able to safely convey the water from the intake to the powerhouse without any leakage that may cause harm to the surrounding environment. Hydraulic fracturing is a major cause of potential leakage in a pressure tunnel. In many occasions, severe leakage problems have been faced that not only have reduced the stability of the rock mass, but also have caused valuable water to be lost from it (Panthi 2009). In addition to the economic loss, leaked water through rock mass may have severe effect on the stability of valley side slopes and the environment.

This paper deals with the assessment on the possibility of hydraulic fracturing along the high pressure tunnel of Upper Tamakoshi Hydroelectric Project (UTKHEP) in Nepal. The project consists of $4746 \mathrm{~m}$ long pressure tunnel, which is subjected to a maximum water pressure of about $4 \mathrm{MPa}$ ( 40 bars or 400 meters water column). Till now no unlined high pressure tunnels have been constructed in the Himalayan region including Nepal and hence Upper Tamakoshi will be the first one of its kind. Therefore, careful assessment and analysis should be pre-conditions for such endeavor. To carry out such an analysis, a design criterion developed and revised continuously with more experience gained from completed projects in Norway has been applied. This criterion is a rule of thumb and is generally used in the earlier phases of the project design. Further, analysis has been carried out using two dimensional numerical modeling code Phase2 (a software).

\section{Project Information}

UTKHEP is a run-of-the river (ROR) scheme with 
daily peaking reservoir. The project lies in Dolakha district and is about $100 \mathrm{~km}$ north east of Kathmandu, Nepal (Figure 1). It utilizes a gross head of $822 \mathrm{~m}$ and a design discharge of 66 cumecs to generate $456 \mathrm{MW}$ of electricity with an average annual energy production of about $2281 \mathrm{GWh}$. In the second stage of the project, water from Rolwaling Khola, a tributary of Tamkoshi River will also be diverted to the peaking reservoir via a transfer tunnel. It will add about $15 \%$ flow in the dry season thus increasing annual energy production to $2448 \mathrm{GWh}$. The first phase of the project is expected to be finished by 2015 and further upgrading by 2017 (UTKHPL 2011).

A 6om long 22m high dam placed at Lamabagar diverts the water from Tamakoshi River through an approximately $7.9 \mathrm{~km}$ long headrace tunnel to an underground powerhouse located at Gongar. In addition to the main intake, the project taps water from a tributary called Bhainse Khola. This water is added to the tunnel at the end of the low pressure tunnel which is approximately 2.9 $\mathrm{km}$ long. The remaining part of the headrace tunnel, approximately $4.9 \mathrm{~km}$ after this is highly pressurized until it meets the surge tunnel leading to the surge arrangement. The powerhouse will be equipped with six 79.5 MW Pelton turbines. The water will then be released back to Tamakoshi River through a tailrace tunnel of length $2.9 \mathrm{~km}$ (Figure 2).

\section{Geology of the Project Area}

The project area is situated about $20 \mathrm{~km}$ north from the Main Central Thrust (MCT). The MCT is a major structural discontinuity in the area, which has roughly east west strike and is dipping towards north in the central Nepal. It separates the lesser Himalayan rock formations from the higher Himalayan rock formations (Figure 1). The project is located in the metamorphic units of higher Himalayas. It mainly consists of micaschist

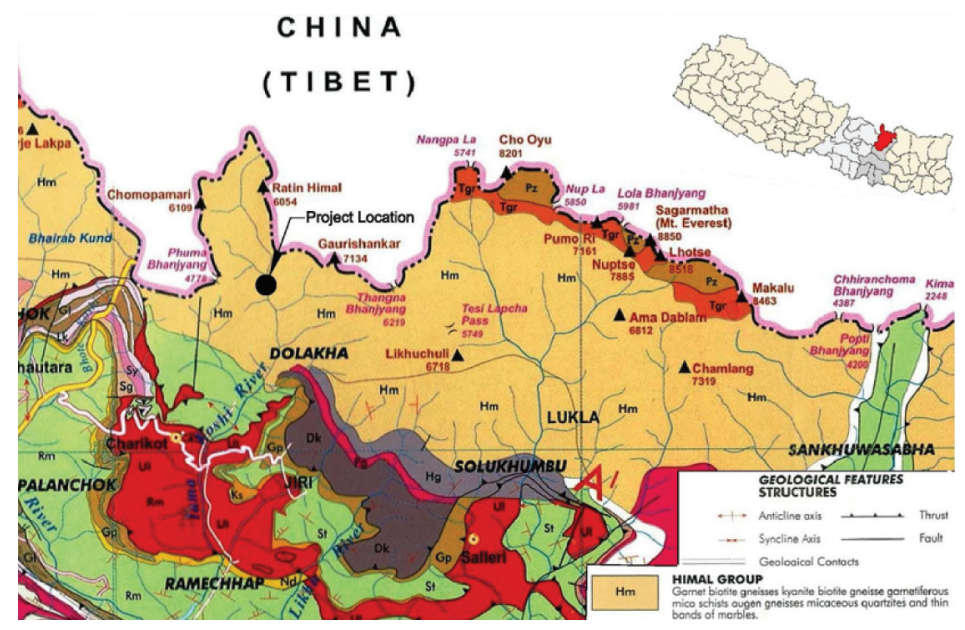

Figure 1. Regional Geology of the Project Area.

(Source: Department of Geology and Mines, Nepal) and banded mica gneiss. The core samples from the headworks and powerhouse area indicate $20 \%$ to $42 \%$ mica content. The rock type varies between schist and banded mica gneiss.

The bedrock along the headrace tunnel is dominated by micaschist and banded mica gneiss. The rock ranges from slightly to moderately weathered, medium hard to hard, medium strong to strong and jointed. The mapping shows that fracturing is more intense along the surface at the outlet compared to the intake. The joint pattern differs
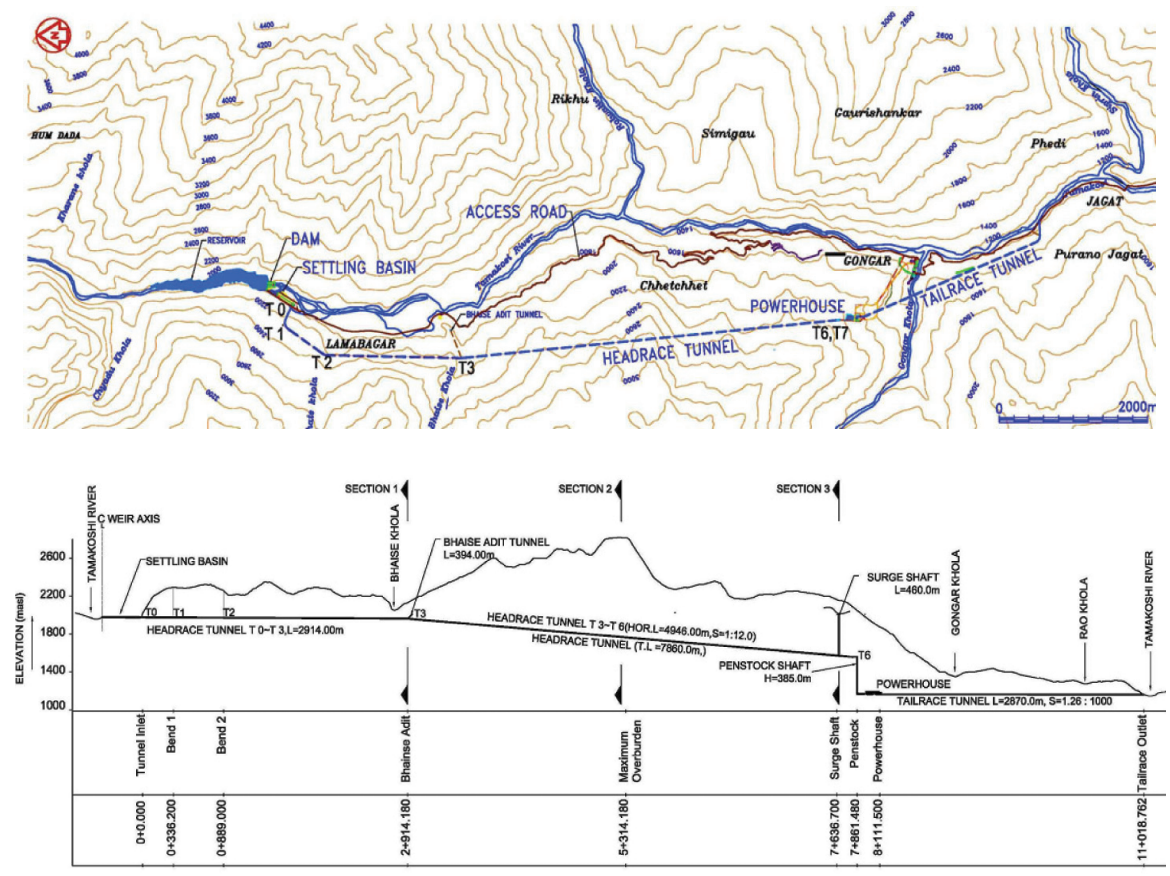

Figure 2. Plan and Profile of Upper Tamakoshi Hydroelectric Project (UTKHEP).

from location to location, which produces variation from massive to highly jointed rock mass (NEA 2005).

The tunnel face mapping performed in the already completed access tunnel to powerhouse shows three major joint sets with random joints. The general strike of the main foliation joint (Jf) ranges from $\mathrm{N} 150-160^{\circ} \mathrm{E}$ and dips towards $45^{-} 65^{\circ} \mathrm{NE}$. Joint set number one (J1) ranges from $\mathrm{N} 120-140^{\circ} \mathrm{E}$ and dips towards $65^{-}-85^{\circ} \mathrm{NE}$. Similarly, the second joint set (J2) ranges from N70$90^{\circ} \mathrm{E}$ and dip towards $55^{-}-85^{\circ} \mathrm{SE}$.

\section{Tamakoshi High Pressure Tunnel}

The Tamakoshi headrace tunnel runs through bedrock almost in north-south direction starting from the right bank at Lamabagar. The rock cover near the intersection with Bhaise Khola from where high pressure tunnel starts is relatively shallow (approximately 170 $\mathrm{m})$. The maximum vertical rock cover in the middle section of the pressure tunnel is more than $1000 \mathrm{~m}$ (Figure 2). The pressure tunnel in UTKHEP is $4746 \mathrm{~m}$ long and experiences a maximum water pressure of about $4 \mathrm{MPa}$ (40 bars).

In order to assess the possibility of hydraulic 
fracturing of the high pressure tunnel, three most representative sections along the alignment are chosen (Figure 2). The first section is at the beginning of the pressure tunnel near the intersection with Bhaise adit. While other two sections are at the stretch which has the maximum rock cover along the whole pressure tunnel (chainage 2400m) and the section at chainage $4746 \mathrm{~m}$ near the surge tank. These three sections are believed to represent the whole pressure tunnel length since the first section has a very low rock cover but also with low hydrostatic pressure; the second section has a maximum rock cover but with medium hydrostatic pressure (2.05 $\mathrm{MPa}$ ) and the third section will experience maximum hydrostatic pressure of about $4 \mathrm{MPa}$ and has rock cover of approximately $590 \mathrm{~m}$.

\section{Analysis Using Deterministic Approach}

Hydraulic fracturing, in principle, is prevented when the hydrostatic pressure within the tunnel is kept less than the minimum in-situ rock stress, or that the time of application of the hydraulic pressure is too short to cause fracturing or opening up of the joints in the rock mass.

To begin with the analysis, a design criterion which has been developed and revised based on the experience from already completed projects in Norway has been applied. This criterion is also called rule of thumb and is expressed by Equation 1 and 2 below. Such approach is generally useful in the earlier phases of project planning and design.

$$
\begin{aligned}
& \gamma \text { r.h. } \cos \alpha>\mathrm{H} \gamma \mathrm{w} \\
& \gamma \mathrm{r} \cdot \mathrm{L} \cdot \cos \beta>\mathrm{H} \gamma \mathrm{w}
\end{aligned}
$$

Figure 3 shows the parameters used in equations 1 and 2. In the figure, $h$ is the vertical depth in metres of point studied; $\mathrm{L}$ is the shortest distance in metres between the surface and the point to be studied, $\alpha$ is the inclination of the shaft, $\beta$ is the average inclination of the valley side, $\mathrm{H}$ is the hydrostatic head in metres and $\gamma \mathrm{r}$ and $\gamma \mathrm{w}$ are the densities of rock and water, which are $2,700 \mathrm{~kg} / \mathrm{m}^{3}$ and $1,000 \mathrm{~kg} / \mathrm{m}^{3}$, respectively.

The criterion (1) was proposed by Selmer-Olsen in 1970, which only considered the inclination of the pressure tunnel. Later, another criterion was added by Bergh-Christensen and Dannevig in 1971, which also takes into account the inclination of the valley side. Benson (1989), has suggested factor of safety for

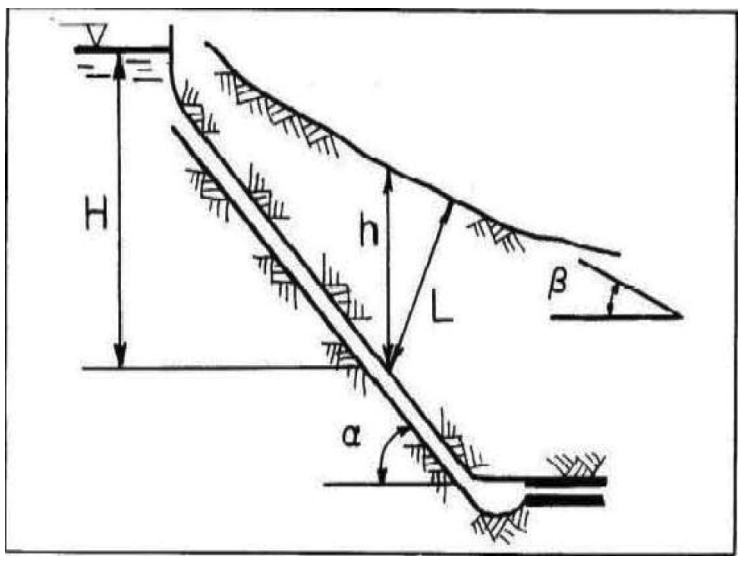

hydraulic conditions during normal operation. A factor of safety of 1.3 has been adopted for the analysis in this case. Water hammer transients are not considered since the time of application of these transient periods are too short to cause any hydraulic fracturing. The results of the calculations are shown in Table 1.

\begin{tabular}{|l|c|c|c|} 
& Section & Section & Section \\
\hline & at 0m & at 2400m & at 4746m \\
$\mathrm{g}_{\mathrm{r}}\left(\mathrm{kg} / \mathrm{m}^{3}\right)$ & 2700 & 2700 & 2700 \\
$\mathrm{H}(\mathrm{m})$ & 12.5 & 205.0 & 393.0 \\
$\mathrm{a}($ degrees $)$ & 5 & 5 & 5 \\
$\mathrm{~b}($ degrees $)$ & 29 & 54 & 36 \\
$\mathrm{~h}(\mathrm{~m})$ & 169 & 1033 & 583 \\
$\mathrm{~L}(\mathrm{~m})$ & 147 & 732 & 455 \\
Criteria & & & \\
$\mathrm{g}_{\mathrm{r}} \mathrm{h}$ cosa & 454564 & 2778487 & 1568110 \\
$\mathrm{~g}_{\mathrm{r}} \mathrm{L}$ cosb & 347137 & 1161699 & 993877 \\
$\mathrm{H} \mathrm{g}_{\mathrm{w}}$ & 12500 & 205000 & 393000 \\
Factor of safety & & & \\
Criteria 1 & 36 & 13.6 & 4.0 \\
Criteria 2 & 28 & 5.67 & 2.5 \\
\hline
\end{tabular}

Table 1. Check for Hydraulic Fracturing at High Pressure Tunnel Using Deterministic Model.

The calculations in Table 1 show that for Section 1, despite the low rock cover, it is very safe against fracturing because the hydrostatic head is also very low (only 1.25 bar). For Section 2, the factor of safety is fairly high and seems safe, meaning weight of the rock mass is able to withstand the water pressure. For the third section, the factor of safety for the second criteria (Equation 2) is 2.5 , which implies that it is also safe against hydraulic fracturing.

However, these rules of thumb use simple equilibrium principles, which consider only gravitational stresses and hence take into account only the confinement provided by the rock cover. In valley sides like the one where the pressure tunnel for UTKHEP is located, the stress regime is mainly dominated by topographic stresses, the magnitude of which is dependent on both gravity induced stress and tectonic stress. Since these rules do not take into account the tectonic horizontal stresses it is important that more comprehensive study is carried out. To satisfy this requirement, the numerical modeling was carried to look on the rock stress condition
Figure 3. Parameters for Deterministic Model (Edvardsson and Broch 2002). in the valleyside and the changed stress regime after excavation.

It is important to be highlighted here that proper understanding and quantification of the input parameters is very essential in obtaining good results using numerical modeling. The next section deals with the quantification of input parameters for numerical modeling based on the geological investigations carried out. 


\section{Quantification of Input Parameters for Numerical Model}

The input parameters required for numerical modeling has been estimated based on the geological investigations performed in the project area. Relevant parameters have been estimated by using the RocLab Program and Hoek - Brown criteria (Equation 3).

$$
\sigma_{1}=\sigma_{3}+\sigma_{\mathrm{ci}}\left[m_{b} \frac{\sigma_{3}}{\sigma_{\mathrm{ci}}}+s\right]^{a}
$$

\section{where}

$\sigma_{1}$ and $\sigma_{3}$ are maximum and minimum principle stresses

$m_{b}$ is the value of Hoek - Brown constant $m_{i}$ for the rock mass

$\mathrm{s}$ and $\mathrm{a}$ are constants that depend on the rock mass characteristics

$\sigma_{\mathrm{ci}}$ is the uniaxial compressive strength of the intact rock piece

According to Hoek (2007), in order to use the Hoek-Brown criterion for estimating the strength and deformability of jointed rock masses, three properties of the rock mass have to be estimated, which are:

- Uniaxial compressive strength $\sigma_{\mathrm{ci}}$ of the intact rock pieces,

- Value of the Hoek-Brown constant mi for intact rock pieces, and

- Value of the geological strength Index GSI for the rock mass.

\section{Uniaxial compressive strength}

The uniaxial compressive strength of the intact rock has been estimated based on the UCS tests on the core samples obtained from drilling performed at the surge tank site. The tests performed in 35 samples from surge tank drillings show that the range varies from $5 \mathrm{MPa}$ to $87 \mathrm{MPa}$ with an average value of $35 \mathrm{MPa}$. These samples have been recovered from drilling depths from $13 \mathrm{~m}$ to $350 \mathrm{~m}$ from the surface. The lowest value is obtained from a core sample from a depth of $24 \mathrm{~m}$, which probably is influenced by weathering due to near surface location. But UCS value as low as $17 \mathrm{MPa}$ has also been found in a core sample from a depth of $335 \mathrm{~m}$. This value is relatively low as compared to the typical values of schistose gneiss, which is most likely due to the high mica content. Another reason could be related to the strength anisotropy in the rock mass caused by schistocity angle. In most cases, it is difficult to obtain core samples at an angle which is normal to the foliation or the schistocity plane. In the case of UTKHEP, the drilling has been done in vertical direction which means that the schistocity angle in the samples is not perpendicular to the direction of loading. Hence, the compressive strengths obtained from these tests are influenced by schistocity angle. For the purpose of analysis, the average UCS of $35 \mathrm{MPa}$ has been used.

\section{Hoek-Brown Constant, mi and Disturbance Factor}

The value of mi mentioned in Hoek (2007) and in the RocLab for schist gives a range, which is $10 \pm 3$. This value could have been higher upto the range of $28 \pm 5$, which is the mi value for gneiss. Since rock mass in UTKHEP is highly schistose and has high content of mica, the value for schist is more relevant. Hence, the value of 10 is adopted for mi. The disturbance factor is taken as o for the analysis assuming there will be controlled and careful blasting.

\section{Geological Strength Index (GSI)}

The most important component of the HoekBrown criteria is the process of reducing the material properties such as oci and mi for their 'laboratory' values to appropriate in-situ rock mass. This may be accomplished through the Geological Strength Index GSI (Hoek and Marinos 2000).The description of the rock structure in UTKHEP matches with the category of 'very blocky'. The rock mass is partially disturbed and interlocked with angular blocks formed by three joint sets. According to the access tunnel log, the joints are slightly to moderately weathered and altered surfaces. Based on these observations, the GSI value for the rock mass is estimated to be in a range of 45 to 55 . A single value of 50 is adopted as an input parameter.

\section{Modulus of Deformation}

Modulus of deformation is the ratio of stress to corresponding strain during the loading of a rock mass including elastic and inelastic behavior whereas the Young's modulus of elasticity is the same ratio within elastic limits. Since jointed rock mass does not behave elastically, deformation modulus is used instead of Young's modulus of elasticity. Rock specimens tested in laboratory gives a higher modulus than the in-situ rock mass because it contains fewer discontinuities and is more continuous structure as compared to the in-situ rock mass. Hence, in-situ tests on a large specimen are required to produce reliable results.

All in-situ measurements of the static modulus of deformation used today are time-consuming and imply notable costs and operational difficulties. Because of this, the deformation modulus is often estimated indirectly from classification systems (Palmstrom and Singh 2001). Also, the values obtained from different tests often differ considerably (Nilsen and Palmstrom 2000). Moreover, the test results may not be available before a certain stage of project development when they are required. Because of these limitations, the modulus of deformation is often estimated using empirical relations proposed by different scholars. The deformation modulus is calculated using the relationship proposed by Hoek 2007. The estimated value is given in Table 3. Input results calculated using RocLab are presented in Table 2.

\section{In-Situ Stresses}

The in-situ rock stress has been measured by $3 \mathrm{D}^{-}$ 
overcoring at three locations in a test adit near the powerhouse area. The summary of the results are shown in Table 3.

As seen in table 3, the direction of the horizontal stresses at $330 \mathrm{~m}$ and $364 \mathrm{~m}$ rock cover vary at about an

\begin{tabular}{|c|c|c|c|}
\hline \multicolumn{2}{|l|}{ Input Data } & \multicolumn{2}{|l|}{ Hoek Brown Criterion } \\
\hline $\begin{array}{l}\text { Intact Uniaxial } \\
\text { comp. strength, } \\
\mathrm{s}_{\mathrm{ci}}\end{array}$ & $35 \mathrm{MPa}$ & $\mathrm{mb}$ & 1.677 \\
\hline GSI & 50 & $\mathrm{~s}$ & 0.004 \\
\hline$m_{i}$ & 10 & $a$ & 0.506 \\
\hline$D$ & 0 & Rock Mass Parameters & \\
\hline $\begin{array}{l}\text { Intact Modu- } \\
\text { lus, } \mathrm{E}_{\mathrm{i}}\end{array}$ & 30767 & Tensile Strength, $\mathrm{s}_{\mathrm{t}}$ & $-0.081 \mathrm{MPa}$ \\
\hline \multicolumn{2}{|c|}{ Failure Envelope Range } & Uniaxial comp. strength, $\mathrm{s}_{\mathrm{c}}$ & $2.108 \mathrm{MPa}$ \\
\hline Application & General & Global Strength, $\mathrm{s}_{\mathrm{cm}}$ & $6.102 \mathrm{MPa}$ \\
\hline$s_{3 \max }$ & $8.75 \mathrm{MPa}$ & Deformation Modulus, $\mathrm{E}_{\mathrm{rm}}$ & $9451.19 \mathrm{MPa}$ \\
\hline Density & $\begin{array}{l}0.0275 \mathrm{MN} / \\
\mathrm{m}^{3}\end{array}$ & & \\
\hline $\begin{array}{l}\text { Modulus of } \\
\text { elasticity }\end{array}$ & $30.7 \mathrm{GPa}$ & & \\
\hline Poisson's ratio & 0.2 & & \\
\hline \multicolumn{4}{|l|}{ Mohr-Coulomb Fit } \\
\hline$c$ and $f$ & $\begin{array}{r}1.74 \mathrm{MPa} \\
\text { and } 30.52^{\circ}\end{array}$ & & \\
\hline
\end{tabular}

Table 2. Needed Input Results from Lab Test and Using RocLab.

angle of 300 and the remaining measurement shows that the stress direction varies by about 900 from the previous two measurements. Hence for the purpose of analyzing on the possibility of hydraulic fracturing, both

\begin{tabular}{|c|c|c|c|c|}
\hline Location, $\mathrm{m}$ inside tunnel portal & & 280 & 400 & 500 \\
\hline Rock cover, m & & 330 & 364 & 408 \\
\hline \multirow{3}{*}{$\begin{array}{l}\text { Measured value of } \\
\text { In-situ stress, Mpa }\end{array}$} & $s_{v}$ & 8.2 & 6.7 & 12 \\
\hline & $s_{\text {hmax }}$ & $21.2\left(18.5^{0}\right)$ & $14.5\left(42.7^{0}\right)$ & $16.8\left(111.3^{0}\right)$ \\
\hline & $\mathrm{S}_{\mathrm{hmin}}$ & $11.2\left(108.5^{\circ}\right)$ & $8.1\left(133.7^{0}\right)$ & $9.1\left(21.3^{0}\right)$ \\
\hline \multirow{2}{*}{ Stress ratio } & $\mathrm{S}_{\mathrm{hmax}} / \mathrm{S}_{\mathrm{v}}$ & 2.59 & 2.16 & 1.40 \\
\hline & $\mathrm{S}_{\mathrm{hmin}} / \mathrm{s}_{\mathrm{v}}$ & 1.37 & 1.21 & 0.76 \\
\hline \multirow{2}{*}{$\begin{array}{l}\text { Theoretical value of Insitu } \\
\text { stress, Mpa }\end{array}$} & $s_{v}$ & 8.85 & 9.83 & 10.99 \\
\hline & $s_{h}$ & 2.21 & 2.46 & 3.10 \\
\hline Density of rock, $\mathrm{kg} / \mathrm{m}^{3}$ & & 2733 & 2754 & 2747 \\
\hline Poisson's ratio & & 0.2 & 0.2 & 0.22 \\
\hline
\end{tabular}

Table 3. Summary of In-Situ Stress Measurement Results in a Test Adit (NEA 2008).

the in-plane and out-of-plane stress ratios have been assumed the same. This assumption keeps the prediction on a safer side since hydraulic fracturing occurs when the hydrostatic pressure in the tunnel exceeds the minimum principal stress. The horizontal stress may not always be the least of the three values and hence critical for hydraulic fracturing. But for deep excavations without topographic influence, this is mostly close to the reality.
The horizontal stress induced by gravity is only a small part of the total horizontal stress. The total horizontal stress is often much higher than the horizontal stress, which is induced by gravity alone. This is because of the tectonic movement of the earth crust which produces horizontal tectonic stresses (Nilsen and Thidemann 19 93). Hence, it is considered that the horizontal plane will be the critical one in case of the Upper Tamakoshi Pressure tunnel.

The horizontal stress is a combination of stress due to gravity and tectonic stress (Panthi 2011) and can be calculated by Equation 4 below:

$$
\sigma_{h}=\frac{v}{1-v} \sigma_{v}+\sigma_{t e c}
$$

where

$\sigma_{\mathrm{h}}$ and $\sigma_{\mathrm{v}}$ are the in-situ gravity led horizontal and vertical stresses and otec is the tectonic component of horizontal stress, respectively and $\mathrm{v}$ is the Poisson's ratio. Using this relation, the tectonic stress has been calculated using measured minimum horizontal and vertical stress presented in Table 3 , which gives an average value of $6.07 \mathrm{Mpa}$. The tectonic stress computed using the overburden of $330 \mathrm{~m}$ has not been used in the analyses because the pressure tunnel mostly has an overburden close to or more than $400 \mathrm{~m}$.

Different values of stress ratios have been calculated for various stretches along the pressure tunnel. The overburden along the pressure tunnel varies from $230 \mathrm{om}$ to $1050 \mathrm{~m}$. Hence, a single value of overburden or stress ratio along the whole tunnel will not be representative of the actual stress condition. The pressure tunnel has been divided into 5 different sections and the stress ratios have been calculated based on the mean value of overburden at each stretch (Table 4).

From Table 4, it can be observed that three values of stress ratios could be used as representative of the total tunnel without compromising the quality of desired result namely $0.76,0.5$ and 0.63 . The stress ratios used for models of sections at 0 , $2400 \mathrm{~m}$ and $4746 \mathrm{~m}$ chainage are $0.76,0.5$ and 0.63 , respectively.

\section{Analysis by Two Dimensional}

\section{Numerical Modeling}

The in-situ stress condition along the tunnel has been determined by running Phase2 code with sections along the longitudinal direction using aforementioned stress ratios. The purpose of this analysis is to compare the minor principal stress at in-situ condition with the hydrostatic head, and to find out any possible section where there is not enough confinement to withstand the water pressure and 


\begin{tabular}{|c|c|c|c|c|c|}
\hline Section & Chianage (m) & \multicolumn{3}{|c|}{ Overburden $(\mathbf{m})$} & $\mathbf{s}_{\text {hmin }} / \mathbf{s}_{\mathbf{v}}$ \\
& & Mean & Max & Min & \\
L1 & 0 to $830 \mathrm{~m}$ & 439 & 645 & 227 & 0.76 \\
L2 & 830 to 1825 & 779 & 939 & 652 & 0.54 \\
L3 & 1825 to 2720 & 895 & 1050 & 649 & 0.50 \\
L4 & 2720 to 3590 & 599 & 671 & 510 & 0.63 \\
L5 & 3590 to 4762 & 587 & 641 & 508 & 0.63 \\
\hline
\end{tabular}

Table 4. Details of Divided Tunnel Segments for Calculating Stress Ratios Along the Tunnel.

to perform further analysis in these sections. The headloss in the tunnel has been neglected and elastic analysis has been performed to assess the stress situation. The Phase 2 model for the longitudinal section of the Upper Tamakoshi pressure tunnel is shown in Figure 4. head at the corresponding point in the pressure tunnel. This holds true for all the threes estimated stress ratios. The narrowest margin between these two values is seen at section at the start of the tunnel. The minor principal stress has decreased near the $2400 \mathrm{~m}$ section due to high overburden (more than 1000m) and decrease in the effect of tectonic stress.

Apart from in-situ stress situation, another important aspect is the redistribution of stress around the periphery of the tunnel after excavation. Further analysis is required to check if the stresses will be lowered to such an extent after excavation where hydraulic fracturing could be possible. Same three different sections; i.e. om, $2400 \mathrm{~m}$ and $4746 \mathrm{~m}$ chainage, have been used for the analysis.

At the start of the tunnel, there is the least difference between minor principal stress and hydrostatic head. At $2400 m$ section, there is a decrease in the minor principal stress and also the hydrostatic pressure is significant. The end section has the maximum hydrostatic pressure of approximately $4 \mathrm{MPa}$ and the margin between the minor principal stress and hydrostatic head is low.

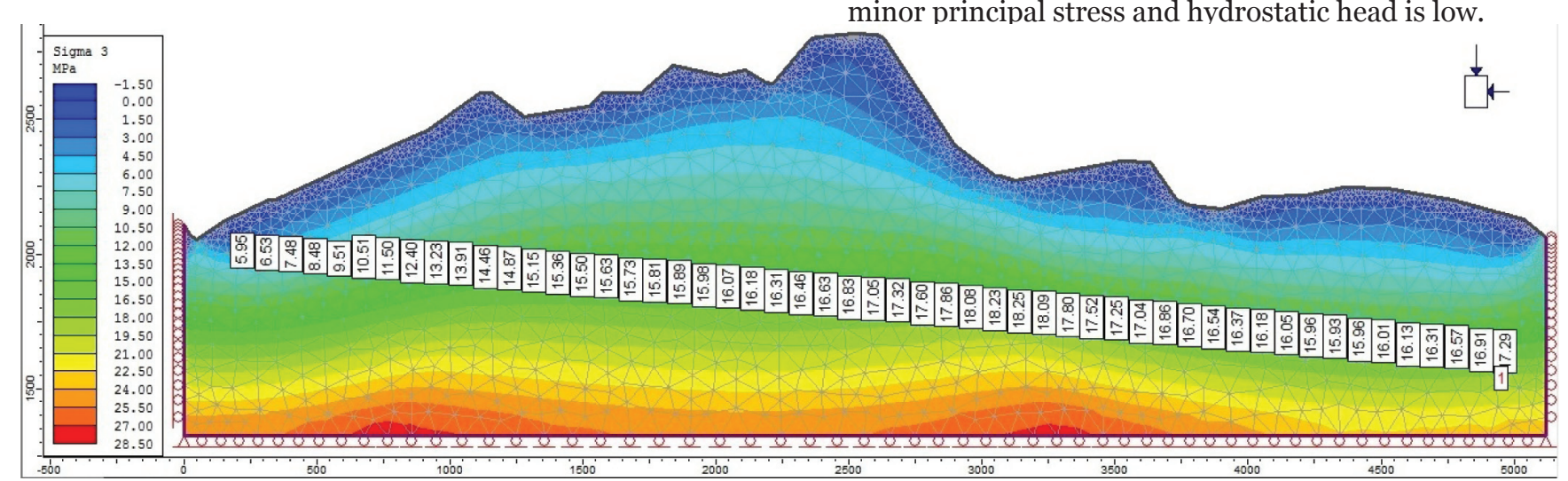

Figure 4. Phase ${ }^{2}$ Model for Longitudinal Section of the Pressure Tunnel Indicating Sigma 3.

\section{In-Situ Stress Situation Along Pressure Tunnel Length}

The plot of the minor principal stress and hydrostatic pressure at in-situ condition is shown in Figure 5.

The result (Figure 5) shows that the minor principal stress at any point is fairly higher than the hydrostatic

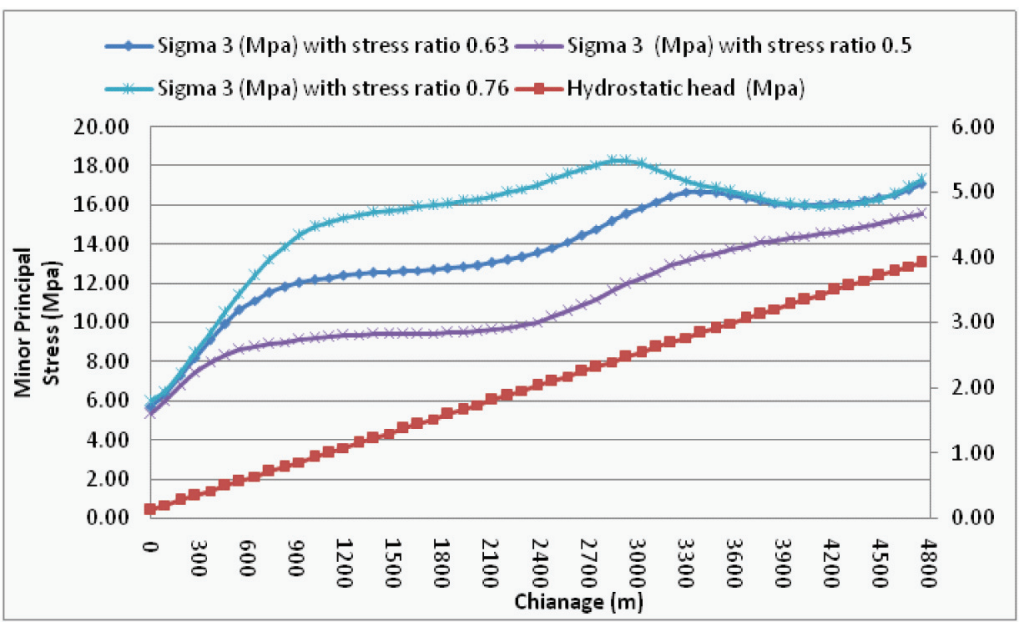

Figure 5. Minor Principal Stress Situation Along

Pressure Tunnel at In-Situ Condition.

\section{Hydraulic Fracturing in Selected Sections}

The effect of topography is very dominant in the stress regime in these sections, which has been represented when the models are built. Valley slope models have been created to simulate the regional stress field which is influenced by topography.

When the ground surface is horizontal, the major principal stress will be equal to the vertical stress. But, as in most cases where hydropower projects are located, the surface is not horizontal and the stress regime is dominated by topography. The major principal stress near the surface will be very close to parallel to the valley slope and the minor principal stress will be perpendicular to it. The reason for this is when rock mass overburden above the valley slope is removed, the topography will rebound and the stresses will be redistributed, which follows the topography as explained above.

Then the excavation of tunnel has been done in these valley models itself and the redistribution of stresses around the openings and its effects on the surrounding rock mass 
occurs. Based on this, the conclusion on whether fracturing will occur or not has been made.

\section{Pressure Tunnel Section at $0 \mathrm{~m}$ Chainage}

Figure 6 represents the valleyside state of minor principle stress (63) condition achieved by Phase 2 modeling. Similarly, Figure 7 represents the state of induced minor principle stress condition ( 63 ) on the periphery of the tunnel after excavation.

As can be seen in these figures, the results indicate that the tunnel walls have been de-stressed due to the excavation and there is stress concentration on the crown. The minor principal stress at the wall is less as compared to the water pressure of about 0.15 MPa. But the region where de-stressing has taken place is limited to a distance of less than $5 \mathrm{~m}$ from the tunnel contour.

\section{Pressure Tunnel Sections at $2400 \mathrm{~m}$ and $47467 \mathrm{~m}$ Chainage.}

Figures 8 to 11 show the stress condition in the valley and the enlarged view of the tunnel after excavation. Although, in-situ stresses have changed at the tunnel

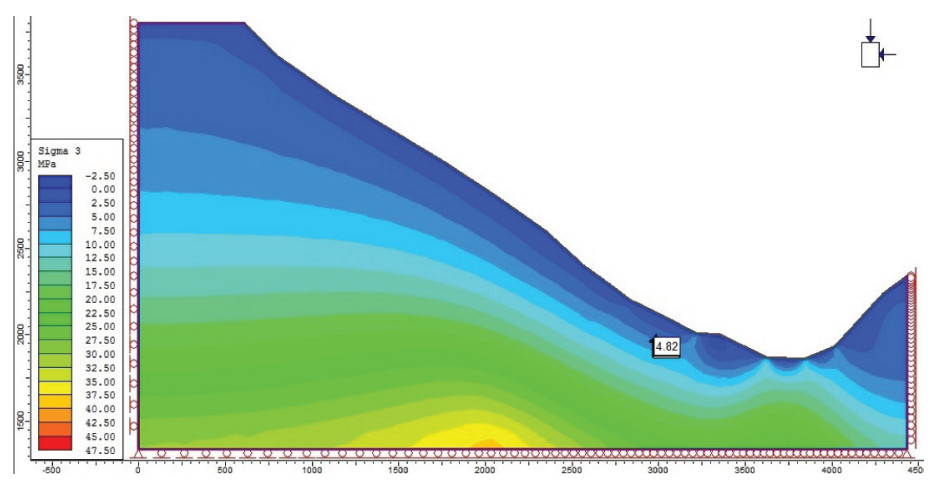

Figure 6. Cross Section with Location of Tunnel in Valley Model at $0 \mathrm{~m}$ chainage.

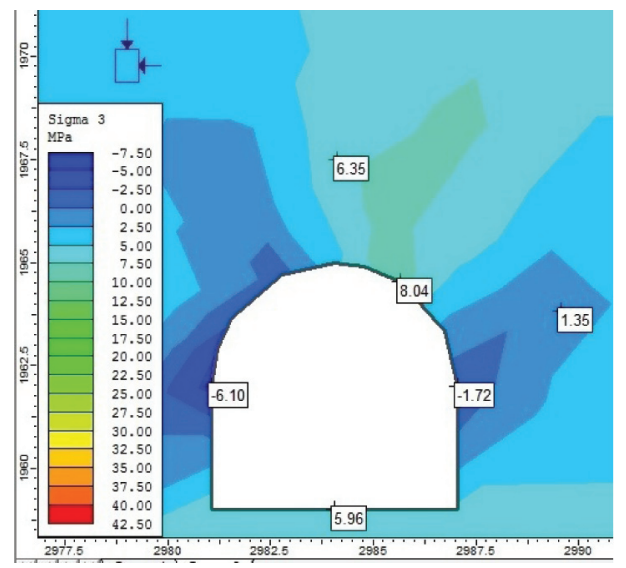

Figure 7.

Enlarged View of Tunnel and Redistributed Stress after Excavation.

location, there is no significant de-stressing around the tunnel periphery to favour hydraulic fracturing. The hydrostatic pressure at normal plant operation at sections at $2400 \mathrm{~m}$ and $4746 \mathrm{~m}$ are $2.05 \mathrm{MPa}$ and $3.92 \mathrm{MPa}$, respectively. Both these values are lower than the minor principal stresses induced after tunnel excavation.

Conclusions
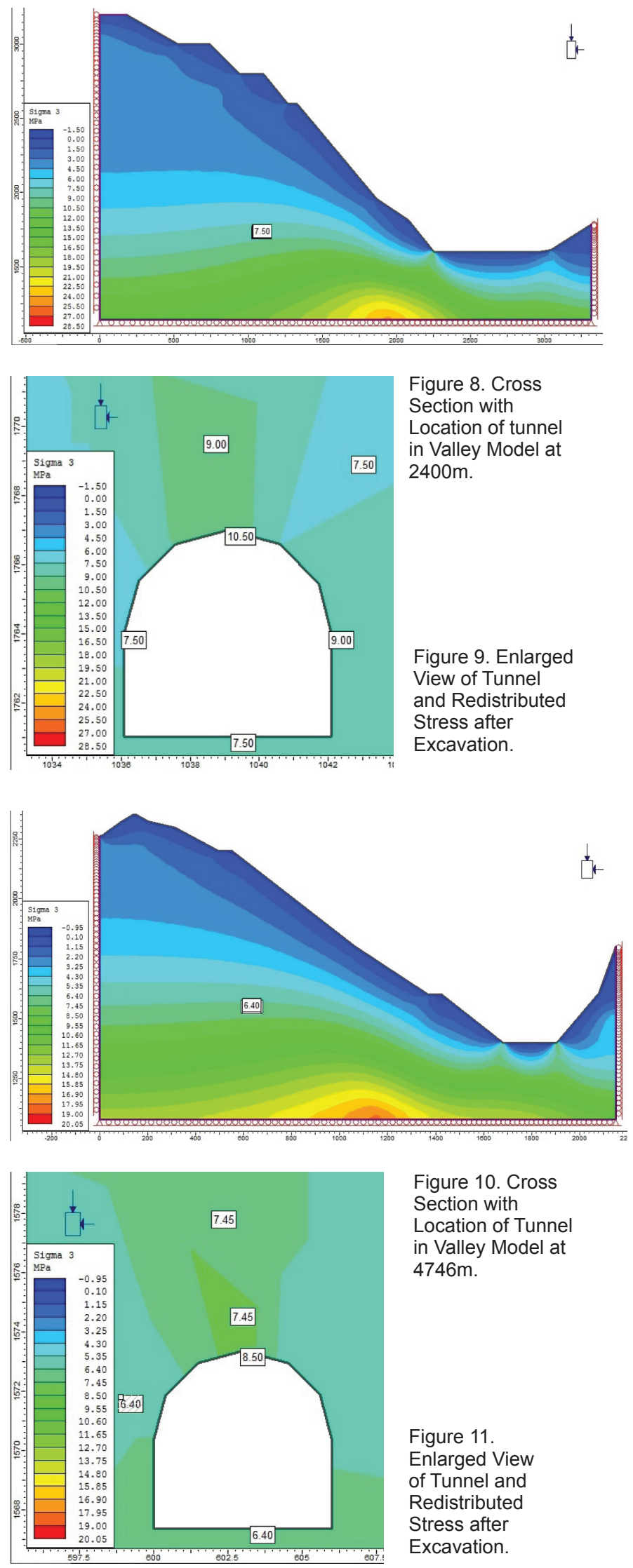

Figure 10. Cross Section with Location of Tunnel in Valley Model at $4746 \mathrm{~m}$.

Figure 11.

Enlarged View of Tunnel and Redistributed Stress after Excavation.

The deterministic approach of analysis indicated that the high pressure tunnel is safe against hydraulic fracturing in all three representative sections selected. However, it should be noted that this approach completely 
neglects the effect of confinement provided to the rock mass by both topographic and tectonic horizontal stresses. In fact, this method oversimplifies the case and therefore a more detailed analysis using 2D numerical modeling was performed.

Based on the results of the geological investigation and their interpretation, a set of input parameters were defined and used in the numerical models. The results of the models representing longitudinal section of the high pressure tunnel revealed that the in-situ stress situation at the rock mass is capable of withstanding the hydrostatic pressure (water head), which the pressure tunnel will experience during its operation.

A detailed analysis carried out to understand the effect of tunnel excavation showed that there is some possibility of fracturing at the starting stretch of the tunnel. But the area around the tunnel contour where the minor principal stress is lower than the hydrostatic pressure is limited to a distance of within 5 meters. The result also showed, for the rest of the tunnel length the in-situ minor principle stresses are sufficient to prevent fracturing.

However, it is emphasized that the fracturing that will occur along the periphery of tunnel due to mobilized stresses after excavation may provide flow paths that may connect in the pre-existing joints in the rock mass. The extent of water leakage from such flow channels will however depend on the extent of connectivity between the joints, their openness, persistence, infilling conditions and the distance from tunnel to the valley slope. Therefore, a careful and detail study on the permeability condition of the rock mass is recommended to be carried out before making any final conclusion on the possible leakage through high pressure tunnel at Upper Tamakoshi Hydroelectric Project.

Bibek Neupane has completed his Masters Degree in Hydropower Development from Norwegian University of Science and Technology (NTNU), has three years in experience various hydropower projects. Current Involvement: Detail design of Lower Manang Marsyangdi Hydroelectric Project (140MW), Manang District, Nepal. Currently, working as Hydropower Engineer at Hydro Consult Pvt. Ltd. Kathmandu, Nepal.

Corresponding Address: bibekneupane@gmail.com

Krishna Kanta Panthi, PhD, is an Associate Professor in Geological Engineering in the Department of Geology and Mineral Resources Engineering, NTNU, Trondheim,
Norway. He has completed his Dr. Ing. degree on the 'Analysis of Engineering Uncertainties Related to Tunneling in Himalayan Rock Mass Conditions' in 2006 from NTNU. He completed his MSc in Hydropower Development in 1998 and MSc in Civil Engineering in 1992. He is the author of many scientific papers related to tunneling, rock slope engineering and hydropower. He has over 15 years of experience in design, construction and planning of tunneling and hydropower projects in the Himalaya (Nepal and India).

Corresponding Address: krishna.panthi@ntnu.no

\section{References}

Benson, R.P., 1989, 'Design of unlined and lined pressure tunnels', Tunnelling and Underground Space Technology 4(2): 155-170.

Edvardsson. S. and E. Broch, 2002, Underground Powerhouses and High Pressure Tunnels, Trondheim: Norwegian University of Science and Technology.

Hoek, E., 2007, Practical Rock Engineering, Toronto: Rocscience Inc. URL: www.rocscience.com.

Hoek, E. and P. Marinos, 2000, 'GSI: A geologically friendly tool for rock mass strength estimation', a paper presented at the

NEA, 2005, UTKHEP Feasibility Study Report, Kathmandu: Nepal Electricity Authority.

NEA, 2008, UTKHEP Final Report on Site Investigation Related to Detailed Design and Tender Documents, Kathmandu: Nepal Electricity Authority.

Nilsen, B., and A. Palmstrom, 2000, Engineering Geology and Rock Engineering, Handbook No. 2, Oslo: Norwegian Group for Rock Mechanics in cooperation with Norwegian Tunneling Society.

Nilsen, B. and A. Thidemann, 1993, Rock Engineering, Hydropower Development Series 9, Trondheim: Norwegian Institute of Technology.

Palmstrom, A. and R. Singh, 2001, 'The deformation modulus of rock masses: Comparisons between in situ tests and indirect estimates', Tunneling and Underground Space Technology 16(3): 115-131.

Panthi, K.K. and B. Nilsen, 2009, 'Uncertainty analysis for assessing leakage through water tunnels: A case from Nepal Himalaya', Rock Mechanics and Rock Engineering 43(5):629.

Panthi, K.K., 2011, 'Assessment on stress induced instability in a tunnel project of the Himalaya', a paper presented at the 12th ISRM International Congress on Rock Mechanics, Beijing.

UTKHEP, 2011, Project Status Asadh 2068, Kathmandu: Upper Tamakoshi Hydropower Ltd. URL:www. tamakoshihydro.org.np. 